\section{Involvement of industry in review articles published in Annals of the Rheumatic Diseases}

Specifically, I refer to the Review Article on IL-17A by McGonagle et al. ${ }^{1}$ The article is excellent and reads very well, and the authors are highly acknowledged scientists and clinicians, some of them I know personally-nice colleagues and friends. Yet, I was puzzled to find out that the article was written by a professional medical writer sponsored by a company. Although all this information on funding and involvement of medical writers is transparantly provided in the article in the sections on acknowledgements, contributors and funding, the value of such a Review Article may change once the reader becomes aware of the involvement of pharmaceutical industry.

In Review Articles in highly accredited journals like Annals of the Rheumatic Diseases, authors express their views and interpretation of recent findings in the field, usually in a scientifically adequate and, importantly, pharmaceutical industry-independent way! Readers of such Review Articles expect a highly balanced, critical and objective review of the topic of choice. This expectation may not be met if the article is written by professional writers, paid by a company which manufactures a drug approved for a disease that is discussed in such an article.

Clinician rheumatologists are often involved in clinical trials, and all manuscripts on clinical trial data are usually prepared by professional writers hired by the companies, with authors commenting, often substantially, as the manuscript develops. Such a procedure is generally accepted by the scientific community, and it is also understandable since the data of the trial are in fact owned by the company. The situation with Review Articles, however, is strikingly different: if the motivation of such articles is driven by (economic) interests of a third party (industry), such an article gets a certain 'flavour'.

Apart from the principal concerns I have with Review Articles in $A R D$ written by professional medical writers sponsored by industry, I provide a precise example from the article demonstrating potential risks: in figure 4 of the article on $\mathrm{p} 1172^{1}$, it is stated by a simple symbol that secukinumab is effective in many disease domains and manifestations including structural progression in the approved indications psoriasis, psoriatic arthritis (PsA) and ankylosing spondylitis (AS). Although this aspect (structural progression) is not further discussed, neither in the main text nor in the legend of figure 4, the message from figure 4 for the reader is crystal clear: secukinumab inhibits structural progression in both PsA and in AS! As of to date, however, there is only indirect circumstantial and very limited information on potential effects of IL-17 blockade on structural progression in AS, similar to the limited and circumstantial evidence of anti-tumour necrosis factor (TNF) agents on inhibition of AS structural progression. The reported structural progression in AS patients treated with secukinumab over 2 and 4 years, respectively, was indeed low, but there was no comparator group in this trial (uncontrolled data). ${ }^{23}$ In another paper on radiographic progression after 2 years of secukinumab treatment as compared with historical data from AS patients tretated with non-steroidal antiinflammatory drugs
(NSAIDs) only, there was only a statistically non-significant trend for less progression in secukinumab-treated patients as compared with the historical cohort. ${ }^{4}$ A head-to-head study on the effects of secukinumab on radiographic progression in AS with adalimumab as a comparator is ongoing but the results are not available yet. Accordingly, the current evidence on inhibition of strucutral progression by IL-17 is weak, yet figure 4 in the Review Article ${ }^{1}$ suggests a clear inhibitory effect in both PsA and AS. This single example illustrates how apparant subtleties introduced intentionally or by mistake by professional medical writers may dramatically impact on the content and message of such Review Article.

I suggest to the editor and to the editorial board of the Annals of the Rheumatic Diseases to reconsider their policy of acceptance of Review Articles written by professional medical writers sponsored by industry.

\section{Martin Rudwaleit (ㅇ}

Correspondence to Professor Martin Rudwaleit, Internal Medicine and Rheumatology, Klinikum Bielefeld Rosenhöhe, 33647 Bielefeld, Germany; martin.rudwaleir@klinikumbielefeld.de

Contributors The author wrote this article without the contribution of other authors.

Funding The authors have not declared a specific grant for this research from any funding agency in the public, commercial or not-for-profit sectors.

Competing interests During the previous 10 years, the author received honoraria and/or consulting fees and/or travel and accomodation support at scientific meetings from AbbVie, BMS, Celgene, Chugai/Roche, Janssen, Eli Lilly, MSD, Novartis, Pfizer and UCB Pharma.

Patient consent for publication Not required.

Provenance and peer review Not commissioned; internally peer reviewed.

(C) Author(s) (or their employer(s)) 2019. No commercial re-use. See rights and permissions. Published by BMJ.

$$
\text { Check for updates }
$$

To cite Rudwaleit M. Ann Rheum Dis Epub ahead of print: [please include Day Month Year]. doi:10.1136/annrheumdis-2019-216544

Received 26 October 2019

Accepted 30 October 2019

Ann Rheum Dis 2019;0:1. doi:10.1136/annrheumdis-2019-216544

ORCID iD

Martin Rudwaleit http://orcid.org/0000-0001-5445-548X

\section{REFERENCES}

1 McGonagle DG, McInnes IB, Kirkham BW, et al. The role of IL-17A in axial spondyloarthritis and psoriatic arthritis: recent advances and controversies. Ann Rheum Dis 2019;78:1167-78.

2 Braun J, Baraliakos X, Deodhar A, et al. Effect of secukinumab on clinical and radiographic outcomes in ankylosing spondylitis: 2-year results from the randomised phase III measure 1 study. Ann Rheum Dis 2017;76:1070-7.

3 Braun J, Baraliakos X, Deodhar A, et al. Secukinumab shows sustained efficacy and low structural progression in ankylosing spondylitis: 4-year results from the measure 1 study. Rheumatology 2019;58:859-68.

4 Braun J, Haibel $H$, de Hooge M, et al. Spinal radiographic progression over 2 years in ankylosing spondylitis patients treated with secukinumab: a historical cohort comparison. Arthritis Res Ther 2019;21. 